\title{
APOSENTADORIA: PERÍODO DE TRANSFORMAÇÕES E PREPARAÇÃO
}

\author{
RETIREMENT: TRANSFORMATIONS AND PREPARATION PERIOD \\ Débora Puquevicz Romanini' ${ }^{1}$ Antonio Augusto de Paula Xavier²; João Luiz Kovaleski ${ }^{3}$ \\ ${ }^{1}$ CEFET-PR, de romanini@uol.com.br \\ ${ }^{2}$ CEFET-PR, augustopx@brturbo.com \\ ${ }^{3}$ CEFET-PR, kovaleski@pg.cefetpr.br
}

Recebido para publicação em: 10/03/2005

Aceito para publicação em: 05/05/2005

\begin{abstract}
Resumo
O periodo pré-aposentadoria têm proporcionado inúmeros problemas dentro das empresas e na vida pessoal das pessoas que vivenciam este periodo de transformação. No mundo atual, o trabalho ocupou um papel de status na sociedade. O respeito e admiração está vinculado com o emprego $e$ cargo que a pessoa exerce. As pessoas que exercem cargo de chefia têm dificuldade em refletir sobre a aposentadoria, devido a ligação de trabalho, produtividade e status sociais.
\end{abstract}

Palavras-chave: Aposentadoria, Psicologia, Trabalho

\section{Introdução}

O mega-executivo Jack Welch, famoso CEO da General Electric, teve sua aposentadoria anunciada em Setembro de 2002. Com um acordo vantajoso, Welch garantiu um apartamento em Manhattan estimado em 15 milhões de dólares, a compra de ações, computadores, celulares, televisão via satélite, serviço de segurança nas seis casas que possui, além de um salário de 86000 dólares por uma consultoria especial com apenas cinco dias de trabalho por ano. Deixando de lado o fator financeiro, Welch continua dando entrevistas e escrevendo livros sobre sua brilhante gestão na G.E. Apesar de aposentado, Welch tem reconhecimento público pelo seu trabalho, ou seja, "status". Diferente da grande maioria que ao se aposentam, perdem seus objetivos e planos para o futuro.

O trabalho na perspectiva psicológica é uma afirmação da auto-estima e função perante a sociedade. O processo produtivo é assimilado em aspectos fisiológicos, morais, sociais e econômicos. O trabalho ocupa um importante espaço na vida humana. Constitui o significado na vida de todos. As pessoas vivem ao redor de sua atividade profissional. Uma pergunta comum 
quando se conhece uma pessoa é "Onde você trabalha?" ou "O que você faz?". A pessoa é vista conforme o papel que ocupa na organização, seu local e poder que desempenha. O trabalho é o principal organizador da vida humana. Horários, atividades, relacionamentos são determinados conforme exigências do trabalho. Ao se aposentar, grande número de pessoas perdem seu ponto de referência. Não será o fulano da empresa $X$, muitas vezes as organizações se tornam um sobrenome, um ponto de referência e prestígio. As conseqüências muitas vezes são depressões, doenças físicas e emocionais. As transições de etapas ou estágio na vida podem ocasionar grandes crises. Vries (2003), chama este período de "síndrome da aposentadoria".

O aposentado é mencionado em dados estatísticos e registros formais como percentual “inativo". Em outras palavras, à aposentadoria é ligado ócio, sem função. O aposentado se sente descartado, sem planos para o futuro. Por tal motivo, a grande maioria das pessoas não aceita a aposentadoria. Muitos não pensam sobre o assunto e quando acontece vivem momentos de inquietação e crise. O presente artigo destaca a importância do assunto na Gestão de Recursos Humanos. De acordo com Zanelli (1996), incentivar a discussão de suposições tácitas, como os deveres da organização frente ao empregado que se aposenta, provoca uma transformação de valores no nível gerencial e ramifica-se até atingir uma mudança maior, do bem-estar daqueles que enfrentam a transição para a aposentadoria.

\section{Aspectos estatisticos e históricos da aposentadoria}

Hoje, aproximadamente $8 \%$ da população têm mais de 60 anos. Em 2020, serão 13\%. Projeções da ONU mostram que, até 2025, a população idosa do Brasil terá acumulado o maior crescimento entre os países do mundo (1,514\% em 75 anos). A expectativa de vida do brasileiro é 67 anos. Isto tem proporcionado um aumento gradativo do período de aposentadoria.

QUADRO 1 - Estimativas e projeções

\begin{tabular}{|cc|}
\hline $60-64$ anos & $2,7 \%$ \\
$65-69$ anos & $2,0 \%$ \\
$70-74$ anos & $1,5 \%$ \\
$75-79$ anos & $0,9 \%$ \\
80 anos ou + & $0,7 \%$ \\
\hline
\end{tabular}




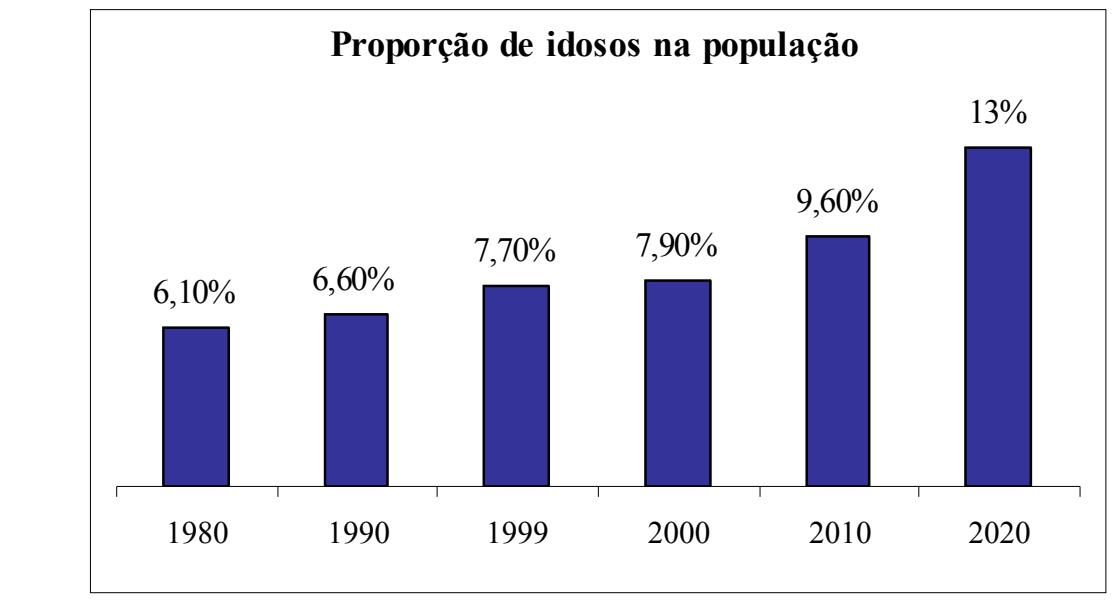

Fonte: DEPIS/FIBGE

Figura 1 - Indicadores construídos com estimativas e projeções calculadas pelo departamento de população e indicadores sociais da fibge.

$\mathrm{Na}$ aposentadoria ocorre a perda de identidade profissional, devido ao término da atividade de trabalho. A grande maioria das pessoas não aceita o término da atividade de produção. Uma pesquisa realizada em 1996 pelo Instituto Gallup e pela empresa de investimentos Paine Webber mostra que $85 \%$ dos americanos economicamente ativos querem continuar trabalhando depois da aposentadoria. Em 1999, outra pesquisa revê-la que 62\% dizem que permaneceram trabalhando porque gostam, $26 \%$ permaneceram trabalhando porque precisam do dinheiro e apenas $12 \%$ pensam em aproveitar mais a família, amigos, viagens e não querem continuar trabalhando. Todavia, nem sempre é possível continuar no mercado de trabalho. Aposentadoria antecipada e forçada são realidade de nosso meio produtivo.

\section{Aspectos físicos e psicológicos da aposentadoria}

Normalmente o estágio da vida onde a maioria das pessoas consegue sua posição de destaque dentro da organização coincide com o período de transformação física devido ao envelhecimento. Mudança na aparência do rosto, os cabelos embranquecidos, a transformação da silhueta e declínio das atividades físicas são causadores da baixa estima. Por estes motivos, muitas pessoas tendem a supervalorizar o poder, a liderança. Eles buscam substituir a atratividade e juventude pelo poder. Segundo Vries (2003), as pessoas de alto nível dentro da empresa, os lideres, são os que mais sofrem com a aposentadoria. A solidão e a depressão aparecem depois que os lideres perdem o poder. A insegurança é tão grande que muitos lideres lançam-se em ações preventivas a qualquer adversário, muitas vezes imaginário, que ameaçam suas posições de poderes. Esta atitude prejudica os interesses da organização e dificulta o desenvolvimento de sucessores aos cargos. "No século passado, o homem nascia, crescia e morria rodeado pelo mesmo ambiente, 
mantendo os mesmos comportamentos, relações e papéis sociais. Hoje uma década vale que uma vida" (TRACTENBERG, 1999).

O cuidado com o organismo ocorre através da manutenção da forma física e da medicina preventiva, mas também com a aceitação das transformações físicas como um processo natural e inevitável. Lembrando que hábitos sedentários aceleram o processo de envelhecimento, e agravam a perda da massa óssea, muscular e problemas cardíacos. O cotidiano de trabalho leva ao sedentarismo. Atividades repetidas e uma dura jornada de trabalho fazem com que o trabalhador esqueça os hábitos saudáveis, a prática de exercícios e esportes. $\mathrm{O}$ estresse também é um sinal dos problemas físicos e psicológicos do limite do homem. As conseqüências físicas acabam por influenciar o comportamento do individuo. Os aspectos físicos causam os aspectos psicológicos porque o corpo e a mente não podem ser estudados separados nos seres humanos.

Verifica-se a ocorrência de uma "dupla aposentadoria" no plano subjetivo: a primeira, legal, por tempo de serviço e a segunda, nem sempre com reconhecimento oficial, mas determinada pelos limites impostos pelo corpo (doenças e/ou idade) e pelo processo de exclusão do mundo do trabalho (CARLOS, 1999).

Os problemas psicológicos da aposentadoria acontecem devido à ligação existente entre trabalho e reconhecimento. Com o fim da vida profissional, muitos outros fatores acabam por extinguir-se como a vida social, o reconhecimento da sociedade, a referência na profissão, os compromissos, os horários, o ser “útil”. A aposentadoria é um período de reestruturação da atividade e valores. É neste período de transformações que a família e amigos evidenciam suas importâncias. Neste momento retorna-se uma vida pessoal deixada de lado; bom relacionamento entre casais, filhos, amigos fora do ambiente de trabalho. Normalmente os trabalhadores são tão absorvidos pelo ambiente de trabalho que acabam deixando suas famílias e amigos. Muitos autores apontam dois meios de equilíbrio do ser humano: o mundo profissional e o mundo familiar. $\mathrm{Na}$ aposentadoria, o primeiro meio é extinto. O momento de aposentadoria pode ser o momento de reflexão e retomada dos vínculos familiares e afetivos.

No filme Confissões de Schimit, o personagem interpretado por Jack Nicholson é um executivo norte-americano da área dos Seguros que ao se aposentar sente-se sem objetivos, desvalorizado. O filme é um alerta sobre o despreparo para a aposentadoria. Também mostra, a dificuldade de desligar-se do mundo de poder e autoridade. O filme mostra que é neste momento que se evidenciam os conflitos pessoais e familiares de uma vida inteira dedicada ao trabalho. E agora a organização os "abandonou-os".

Segundo Bronte (2002), pesquisadores da University College London, identificaram dois cumes em taxas de mortalidade para homens aposentados: um aos 65 anos e o outro em meados dos 80 anos. O primeiro refere-se ao período de ajuste pós-aposentadoria, propício a depressão. 
Teoricamente, aqueles que sobrevivem a esta transformação vivem 15 ou mais anos de vida. Outro estudo alerta que a depressão provoca problemas cardíacos e propicia outras doenças. Ou seja, a depressão provocada no período pós- aposentadoria pode prejudicar a saúde das pessoas. A depressão é uma síndrome de dependência psicológica. A depressão é um processo simbiótico, onde dependência e fantasia delimitam a vida do indivíduo. Esta síndrome tem sido comum no mundo atual. Alguns estudiosos consideram a depressão o mal do século e causadora de inúmeras outras doenças.

O período da aposentadoria não é a causa de todos os problemas ocorridos, mas é o período de mudança em um momento crucial na vida das pessoas: o envelhecimento. Tal fenômeno é irreversível e inevitável, por tal motivo provoca angustia e questionamento sofre o fim da existência. Aposentadoria e velhice estão ligadas e muitos consideram o mesmo fenômeno.

\section{Identidade pessoal, profissional e social}

O sujeito não pode estar separado da subjetividade, do seu eu individual e de um social. Assim a coletividade da qual participa e compartilha vem a formar a sua subjetividade, seja no trabalho, em casa ou numa roda de amigos criando ou repetindo coisas, mas há sempre algo diferente (MOHAUPT, 2003).

A aposentadoria é um momento de mudança na vida das pessoas. Com certeza, este período será resultante da maneira como foi organizada a vida, a importância dada ao trabalho e os vínculos com o sistema social. Cada pessoa investe mais ou menos na vida profissional segundo suas necessidades, suas motivações e suas aspirações. A aposentadoria é o momento de reestruturação da identidade pessoal e estabelecimento de novos pontos de referência.

Segundo Santos (1990), o sujeito que se aposenta sofre não apenas as mudanças naturais do processo de envelhecimento, mas deve também integrar um certo número de modificações acarretadas pela perda de identidade sócio-profissional. $\mathrm{O}$ autor faz uma interessante observação:

\footnotetext{
"Quando uma classe profissional tem um problema qualquer que não encontra solução, ela pode fazer greve. E nós, os aposentados? O que a gente pode fazer? Voltar a trabalhar como forma de pressão? Através dessas questões o sujeito traduzia a ausência de poder de pressão dos aposentados. O que quer que façam, eles não mudarão a ordem social. Eles não podem mais incomodar a sociedade para que ela se volte para seus problemas. O sujeito aposentado perde seu poder social. Isso pode acarretar um afastamento, um isolamento social".
}

Refletindo sobre os argumentos da autora, pode-se observar a transferência da identidade pessoal para identidade profissional e social. No momento da aposentadoria vive-se um período de crise da identidade pessoal. Isso se deve ao importante lugar ocupado pelo papel profissional na 
atualidade. O papel profissional foi supervalorizado como fonte geradora de engajamento social, sucesso, poder e reconhecimento.

A associação entre velhice e aposentadoria faz com que a sociedade relacione o aposentado como um agente de bens e serviços, e conseqüentemente, marginalizado nos contextos sociais pela perda do seu valor produtivo.

\section{Metodologia de pesquisa}

A pesquisa foi realizada através de entrevistas e questionários em uma Instituição Pública com 50 anos de fundação. Esta Instituição possui 195 funcionários com formação superior, técnico e formação fundamental. A amostra de 35 funcionários foi devidamente selecionada conforme o cargo e chefia exercido e os anos para a aposentadoria. Foram selecionados 19 funcionários com cargos de chefias e 16 funcionários sem cargos de chefias. Dentre os funcionários com cargo de chefia encontram-se engenheiros, administradores, contadores e técnicos de diversas áreas como informática, administrativo, tesouraria, licitações.

\section{Pesquisa de campo}

Foi aplicado um questionário aos funcionários relacionados, divididos em duas categorias principais, levando-se em consideração o tempo que falta para sua aposentadoria e se possui ou não cargo de chefia, sendo que os percentuais de resposta encontram-se detalhados abaixo:

TABELA 1 - Pesquisa de campo - Entrevista sobre aposentadoria

Acham que se perde a capacidade produtiva com os anos

\begin{tabular}{|l|c|c|c|c|}
\hline \multicolumn{1}{|c|}{ Período para a aposentadoria } & Mais de 15 anos & $\mathbf{1 5 - 1 1}$ anos & $\mathbf{1 0 - 5}$ anos & Menos de 5 anos \\
\hline Sim & - & $64,3 \%$ & $80 \%$ & $71,4 \%$ \\
\hline Não & $100 \%$ & $35,7 \%$ & $20 \%$ & $28,6 \%$ \\
\hline
\end{tabular}

\begin{tabular}{|l|c|c|}
\hline Cargo de chefia & Possui & Não possui \\
\hline Sim & $50 \%$ & $76,5 \%$ \\
\hline Não & $50 \%$ & $23,5 \%$ \\
\hline
\end{tabular}

Já pensaram sobre o assunto da aposentadoria

\begin{tabular}{|l|c|c|c|c|}
\hline \multicolumn{1}{|c|}{ Período para a aposentadoria } & Mais de 15 anos & $\mathbf{1 5 - 1 1}$ anos & $\mathbf{1 0 - 5}$ anos & Menos de 5 anos \\
\hline Sim, vagamente. & - & - & $20 \%$ & $14,3 \%$ \\
\hline $\begin{array}{l}\text { Sim, fica feliz com a aposentadoria, } \\
\text { terá mais tempo ao lazer. }\end{array}$ & $25 \%$ & $69,3 \%$ & $30 \%$ & $42,8 \%$ \\
\hline Não, nunca pensou sobre o assunto. & $50 \%$ & $21,4 \%$ & $20 \%$ & $14,3 \%$ \\
\hline $\begin{array}{l}\text { Não, prefere não pensar sobre isso, } \\
\text { fica deprimido. }\end{array}$ & $25 \%$ & $14,3 \%$ & $30 \%$ & $28,6 \%$ \\
\hline
\end{tabular}




\begin{tabular}{|l|c|c|}
\hline \multicolumn{1}{|c|}{ Cargo de chefia } & Possui & Não possui \\
\hline Sim, vagamente. & $11,1 \%$ & $5,9 \%$ \\
\hline $\begin{array}{l}\text { Sim, fica feliz com a aposentadoria, terá mais tempo } \\
\text { ao lazer. }\end{array}$ & $38,9 \%$ & $52,9 \%$ \\
\hline Não, nunca pensou sobre o assunto. & $16,7 \%$ & $29,4 \%$ \\
\hline Não, prefere não pensar sobre isso, fica deprimido. & $33,3 \%$ & $11,8 \%$ \\
\hline
\end{tabular}

Pretendem continuar a trabalhar depois da aposentadoria

\begin{tabular}{|l|c|c|c|c|}
\hline \multicolumn{1}{|c|}{ Período para a aposentadoria } & Mais de 15 anos & $\mathbf{1 5 - 1 1}$ anos & $\mathbf{1 0 - 5}$ anos & $\begin{array}{c}\text { Menos de 5 } \\
\text { anos }\end{array}$ \\
\hline Sim & $100 \%$ & $78,6 \%$ & $100 \%$ & $85,7 \%$ \\
\hline Não & - & $21,4 \%$ & - & $14,3 \%$ \\
\hline
\end{tabular}

Motivos para continuar trabalhando

\begin{tabular}{|l|c|c|c|c|}
\hline \multicolumn{1}{|c|}{ Período para a aposentadoria } & Mais de 15 anos & $\mathbf{1 5 - 1 1}$ anos & $\mathbf{1 0 - 5}$ anos & $\begin{array}{c}\text { Menos de 5 } \\
\text { anos }\end{array}$ \\
\hline Gosta do que faz & $50 \%$ & $72,7 \%$ & $80 \%$ & $50 \%$ \\
\hline Precisa do dinheiro & $50 \%$ & $27,3 \%$ & $20 \%$ & $50 \%$ \\
\hline
\end{tabular}

Pretendem continuar a trabalhar depois da aposentadoria

\begin{tabular}{|c|c|c|}
\hline Cargo de chefia & Possui & Não possui \\
\hline Sim & $94,4 \%$ & $82,4 \%$ \\
\hline Não & $5,60 \%$ & $17,6 \%$ \\
\hline \multicolumn{3}{|l|}{ Motivos para continuar trabalhando } \\
\hline Cargo de chefia & Possui & Não possui \\
\hline Gosta do que faz & $82,3 \%$ & $50 \%$ \\
\hline Precisa do dinheiro & $17,7 \%$ & $50 \%$ \\
\hline
\end{tabular}

Dos que pretendem continuar trabalhando, caso não permaneçam na empresa procurariam:

\begin{tabular}{|l|c|c|c|c|}
\hline \multicolumn{1}{|c|}{ Período para a aposentadoria } & Mais de 15 anos & $\mathbf{1 5 - 1 1}$ anos & $\mathbf{1 0 - 5}$ anos & $\begin{array}{c}\text { Menos de 5 } \\
\text { anos }\end{array}$ \\
\hline Outro emprego & $25 \%$ & $36,4 \%$ & $30 \%$ & $50 \%$ \\
\hline Negócio próprio & $75 \%$ & $63,6 \%$ & $70 \%$ & $50 \%$ \\
\hline
\end{tabular}

\begin{tabular}{|l|c|c|}
\hline \multicolumn{1}{|c|}{ Cargo de chefia } & Possui & Não possui \\
\hline Outro emprego & $11,8 \%$ & $64,3 \%$ \\
\hline Negócio próprio & $88,2 \%$ & $35,7 \%$ \\
\hline
\end{tabular}

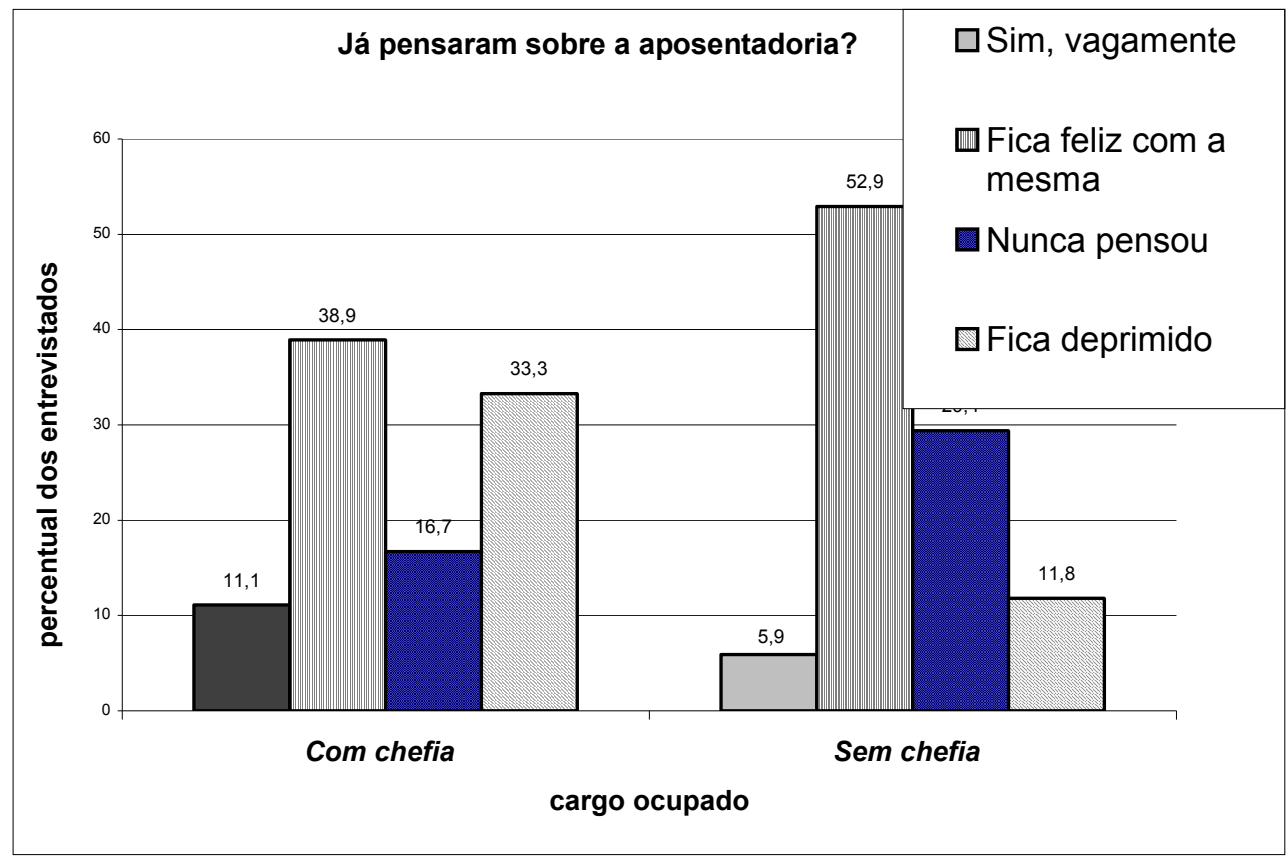

Gráfico 1 - Sentimento sobre aposentadoria x cargo ocupado 


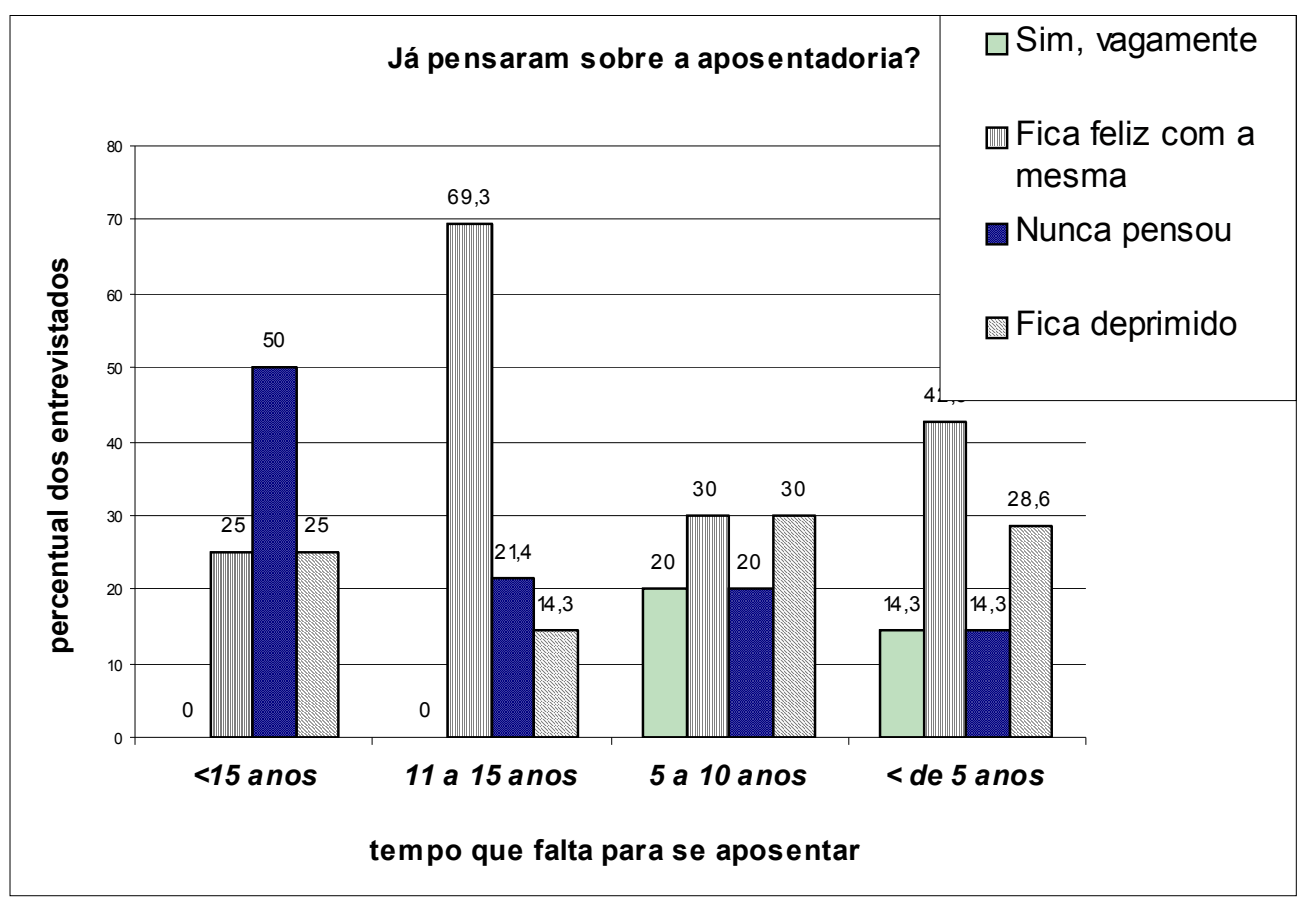

Gráfico 2 - Sentimento sobre aposentadoria $\mathrm{x}$ tempo que falta para se aposentar

\section{Análise da pesquisa de campo}

Todos os entrevistados concordam que os aposentados no Brasil não são respeitados. "O aposentado não tem valor" diz um entrevistado. Sobre a perda de capacidade produtiva com os anos pode-se notar com a pesquisa que com a diminuição dos anos para a aposentadoria, ou seja, o aumento da idade, aumenta a percentagem das pessoas que concordam que há uma certa redução da capacidade produtiva com os anos. Também nota-se que pessoas sem cargo de chefia, no caso dos entrevistados, que realizam trabalho operacional, um elevado número $(76,6 \%)$ concordam com a redução da capacidade produtiva com os anos. Já os funcionários que exercem cargo de chefia, 50\% concordam com a redução da capacidade produtiva com os anos e 50\% não concordam com a afirmação.

Sobre as perguntas relacionadas à aposentadoria observa-se que um maior número de pessoas que não tem cargo de chefia fica feliz com a aposentaria $(52,9 \%)$ comparada com aquelas que tem cargo de chefia (38,9\%). Confirmando que o trabalho e principalmente o poder, a liderança, assumem um papel de status na sociedade que é difícil de ser rompido. Também a percentagem de pessoas que ficam deprimidas ao pensar na aposentadoria é maior naquela que ocupam um cargo de chefia. Das pessoas entrevistadas que possuem cargo de chefia 33,3\% ficam deprimida em pensar na aposentadoria. Já as pessoas entrevistadas que não possuem cargo de chefia apenas $11,8 \%$ dizem que ficam deprimida em pensar na aposentadoria. 
A maioria $(94,4 \%)$ dos entrevistados que possuem cargo de chefia dizem que pretendem continuar trabalhando depois da aposentadoria. Sendo que $82,3 \%$ porque gostam e apenas $17,7 \%$ porque precisam do dinheiro. Dos entrevistados que não possuem cargo de chefia $82,7 \%$ pretendem continuar trabalhando e 17,6\% não querem trabalhar depois da aposentadoria. E $50 \%$ dos que pretendem trabalhar justificam que gostam do que fazem e 50\% porque necessitam do dinheiro.

A da análise da pesquisa de campo comprovou a trabalho como status social nas pessoas que exercem cargo de liderança. Muitas vezes, a dificuldade em deixar a vida profissional não está relacionada com problemas financeiros e sim com o papel que o emprego lhe proporciona na sociedade.

\title{
8. Conclusão
}

A relação entre homem e trabalho deve ser questionada. Inúmeros são os casos de dificuldades nas sucessões de cargo, devido à supervalorização do poder. As empresas precisam de auxilio e treinamento para remanejamento de funções, e não uma guerra entre os velhos leões e os novos guerreiros. Muitas empresas encontraram a solução na aposentadoria parcial. Os trabalhadores diminuem seu período de trabalho, mas continuam envolvidos nas atividades da empresa auxiliando, ajudando na evolução dos novos lideres e vivenciando lentamente sua mudança para aposentadoria.

É importante pensar e estudar o assunto para neutralizar o problema, adequando-se a realidade e assumir a transformação como um período a ser vencido. A aposentadoria não é o fim das atividades, e sim o remanejamento e reorganização de outras atividades.

\begin{abstract}
The period before retirement have been providing countless problems in the companies and people's life who live this transformation period. In the current world, the work occupied a status paper in the society. The respect and admiration is entailed with the job and position that the person exercises. People who exercise leadership position have difficulty reflecting about the retirement, due to working connection, productivity and social status.
\end{abstract}

Key words: Retirement, Psychology, Work

\section{Referências}

BRONTE, L. Is retirement dangerous to your health? Across the Board, v. 39, n. 2, p. 52-55, 2002.

CARLOS, S. A.; JACQUES, M. G. C.; LARRATEA, S. V.; HEREDIA, O. C. Identidade, aposentadoria e terceira idade. Est. Interdiscipl. Envelhec., Porto Alegre, v. 1, p. 77-88, 1999.

MANNING, A. Early Retirement? Who, Me? Memphis Magazine. Disponível em: 
http://www.memphismagazine.com. Acesso em: 27 abr.2004.

MOHAUPT, M. L. A subjetividade no mundo da tecnologia. Libertas comunidade. Disponível em: http://www.libertascomunidade.com.br. Acesso em: 26 abr. 2004.

SANTOS, M. F. Identidade e aposentadoria. São Paulo: EPU, 1990.

TRACTENBERG, L. A complexidade nas organizações: futuros desafios para o psicólogo frente à reestruturação competitiva. Revista Psicologia, Ciência e Profissão, v. 19, n. 1, p. 14-29, 1999.

TUOMI, K.; HUUHTANEN, P.; NYKYRI, E; IMARINEN, J. Promotion of work ability, the quality of work and retirement. Occupational Medicine Magazine, v. 51, n. 5, p. 318-324, 2001.

cross ${ }^{\text {ref }}$

VRIES, M. Síndrome da aposentaria. Revista HSM Management, v. 8, n. 41, p.182-190, 2003.

ZANELLI, J. C.; SILVA, N. Programa de preparação para aposentadoria. Florianópolis: Insular, 1996. 